\title{
A Huge Intraabdominal Lump in a Male Patient of 32 Year with Congenital Absence of Left Testis - A Case Report
}

\author{
Ahmed N¹, Hossain MA², Hasan MR ${ }^{3}$, Islam $M^{4}$, Tasnim A ${ }^{5}$, Ajmir S6, Nahar $N^{7}$
}

Conflict of Interest: None

Received: $12-04-2018$

Accepted: 11-09-2018

www.banglajol.info/index.php/JSSMC

\begin{abstract}
Undescended testis is a common risk factor for the testicular neoplasm. The risk of malignancy in an undescended testis is highest when the testis lies in the abdomen. It usually presents with a painless intraabdominal lump. Seminoma is the most common adult germ cell tumour of testis whereas Yolk sac tumour in seen in the pediatric age group. Pure yolk sac testicular tumor in an adult is extremely uncommon. Here we present a case where an adult male presented to us with a painless left sided intraabdominal lump with undescended testis on the same side was previously diagnosed as metastatic adenocarcinoma of unknown primary. In a private hospital he received three cycles of chemotherapy; but the lump did not reduce in size and he was reffered to our care for better management. The lump was excised and histopathological report revealed yolk sac tumour of left testis which is a rare presentation in adult.
\end{abstract}

[J Shaheed Suhrawardy Med Coll 2018; 10(2): 115-117] DOI: https://doi.org/10.3329/jssmc.v10i2.41172

\section{Introduction:}

During fetal development, the testes develop in the abdomen and later descend into the scrotal sac in the third trimester, usually between weeks 28 to $32 .{ }^{1}$ During the descent, it may be arrested anywhere along its tract (cryptorchidism) or may migrate into an abnormal position (ectopic testis). Cryptorchidism, the most common congenital anomaly of the genitourinary tract in males, is encountered in $1 \%$ of boys. ${ }^{2}$

The most common sites of undescended testis are high scrotal (50\%), canalicular (20\%), and abdominal (10\%), bilateral $(10 \%){ }^{2}$ Undescended testes with intra-abdominal mass is more likely to be testicular neoplasm. Testicular cancer is developed in $10 \%$ of the cases with undescended testis. ${ }^{2}$ For this reason, testicular cancer should be considered as the differential diagnosis of an abdominal

1. Dr. Nadim Ahmed, Senior Consultant, Department of Surgery, Shaheed Suhrawardy Medical College \& Hospital, Dhaka

2. Dr. Muhammad Anowar Hossain, Junior Consultant (Surgery), Upazila Helath Complex, Keranigonj, Dhaka

3. Dr. Mohammad Rashedul Hasan, Medical Officer, Department of Surgery, Shaheed Suhrawardy Medical College \& Hospital, Dhaka

4. Dr. Mansurul Islam, Assistant Registrar, Department of Surgery, Shaheed Suhrawardy Medical College \& Hospital, Dhaka

5. Dr. Afrida Tasnim, Honorary Medical Officer, Department of Surgery, Shaheed Suhrawardy Medical College \& Hospital, Dhaka

6. Dr. Sah Ajmir, Honorary Medical Officer, Department of Surgery, Shaheed Suhrawardy Medical College \& Hospital, Dhaka

7. Dr. Nazmun Nahar, Honorary Medical Officer, Department of Surgery, Shaheed Suhrawardy Medical College \& Hospital, Dhaka

Correspondence to: Dr. Nadim Ahmad, Senior Consultant, Department of Surgery, Shaheed Suhrawardy Medical College \& Hospital, Dhaka mass in patients with a nonpalpable testis. The incidence of testicular cancer is considered to be 3 to 48 times greater than in the general population in case of undescended testis. ${ }^{3}$ Various tumor markers are available in the form of alpha fetoprotein $(\alpha-F P)$, beta human chorionic gonadotrophin ( $\beta-\mathrm{HCG})$, lactate dehydrogenase (LDH), and placenta-like alkaline phosphatase (PLAP). They are helpful not only in making the diagnosis but also in formulating a management plan. Their sensitivity and specificity vary according to the type of testicular tumor.

Reason of malignant transformation of undescended testis remains unclear. Two hypotheses have been proposed to explain this association. The first one says that local temperature elevation of an undescended testis is, somehow, procarcinogenic. ${ }^{4}$ The second hypothesis says that an underlying hormonal condition predisposes testicular cancer. ${ }^{4} \mathrm{~A}$ high intra-abdominal temperature has been incriminated as the cause of carcinogenesis in the testis ${ }^{4}$. There may be a decrease in the spermatogenesis, Leidig cell abnormality, and delay in the development of the Sertoli cells in the testis, leading to infertility. Painless enlargement of abdominal testis is the common mode of manifestation in an undescended testis. Rarely, an abdominal testicular neoplasm can present with torsion, massive abdominal mass and pain.

Testicular cancers are highly curable, even in patients with metastatic disease at diagnosis. The prognosis depends upon the histologic type of cancer (seminoma versus nonseminoma), staging, and other features such as tumour markers and type of metastasis. Here we present a case 
report on an adult male with left sided undescended testis presented as intraabdominal testicular tumour.

\section{Case summary:}

A 32 year male, father of two children, presented to the surgery department of Shaheed Suhrawardy Medical College Hospital with the complaints of painless progressive abdominal lump in the left lumber region for 6 months. He also gave history of anorexia and weight loss for same duration. The patient was diagnosed as metastatic adenocarcinoma of unknown primary by FNAC. In a private hospital he received three cycles of chemotherapy; but the lump did not reduce in size and he was reffered to our care for better management. On general examination he was mildly anaemic and his vital parameters were within normal limits. Per abdominal examination revealed an intraabdominal lump measuring about $8 \mathrm{~cm} \times 6 \mathrm{~cm}$ in the left lumber region which was firm in consistency, fixed with surrounding structures having ill-defined margins and irregular surface. There was no organomegaly and accessible lymph nodes were not palpable.

On examination of the inguinoscrotal region the right testis was found to be in place but the left testis was absent from the left scrotal sac.

His Complete blood count revealed Hb level- 8.4 gm/dl,ESR $-44 \mathrm{~mm}$ is $1^{\text {st }}$ hour, $\mathrm{WBC}-10,000 /$ cumm, platelet count $3,30,000 /$ cumm. His serum creatinine, liver function tests, Chest X-ray, and ECG showed normal findings. His ultrasonography of whole abdomen demonstrated a complex soft tissue mass in the left lumber region with central hypoechoic area measuring about $8 \mathrm{~cm} \times 6 \mathrm{~cm}$ suggesting intraabdominal testicular neoplasm. (Fig-1) There was no abdominal lymphadenopathy. His serum alpha fetoprotein $(\alpha-\mathrm{FP})$ level $(1035.41 \mathrm{ng} / \mathrm{ml})$ and beta human chorionic gonadotrophin ( $\beta$-HCG) level (469.6 U/1) were elevated but lactate dehydrogenase (LDH) level was within normal limits. With this clinical scenario our working diagnosis was left sided intraabdominal testicular

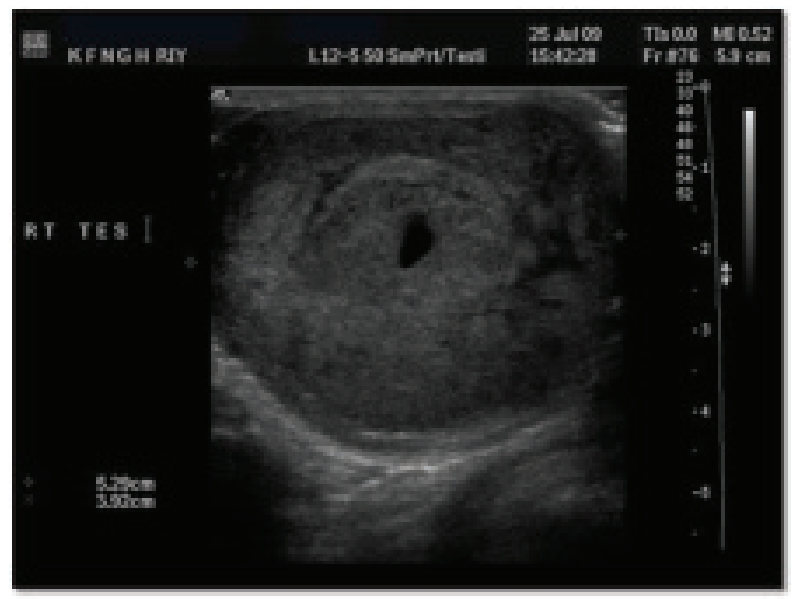

Fig-1: Ultasonographic view on intraabdominal testicular mass

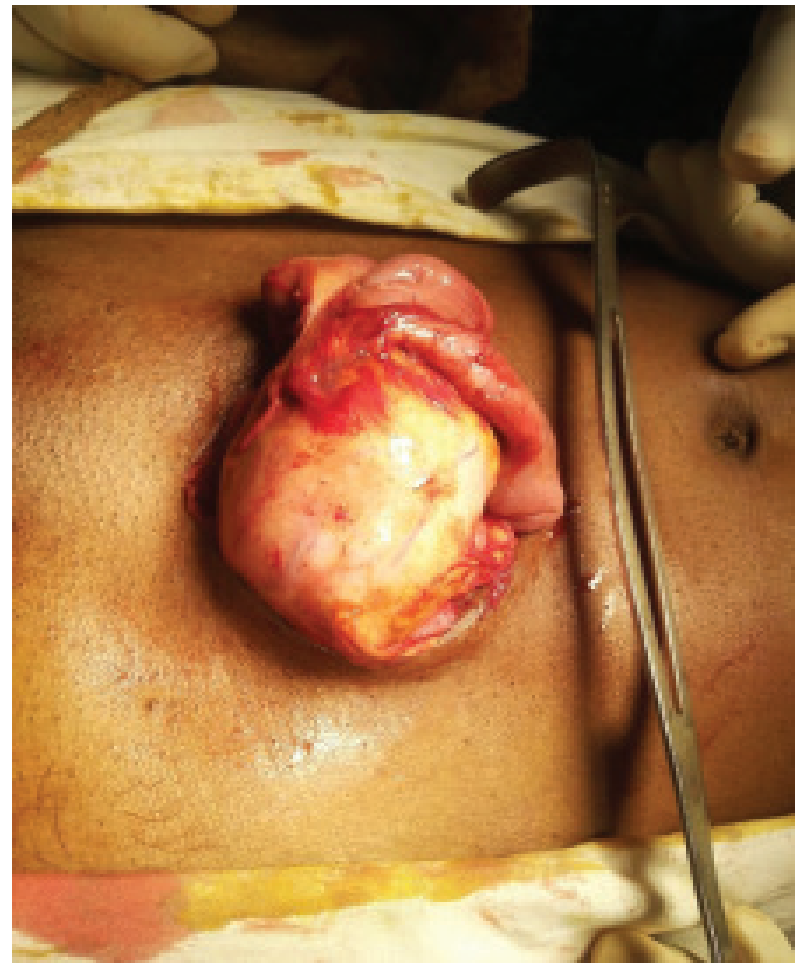

Fig 2: Per-operative view of intraabdominal testicular neoplasm

neoplasm. After correcting anaemia by blood transfusion, the patient underwent diagnostic laparoscopy followed by laparotomy. There was a pedunculated mass in the left lumber region which was attached to the small gut. (Fig-2) There was no abdominal lymphadenopathy. The mass seemed to be testicular neoplasm. Excision of the mass after ligating the feeding vessels was done. His postoperative period was uneventful. His histopathological report showed left sided yolk sac tumour. (Fig-3) He was

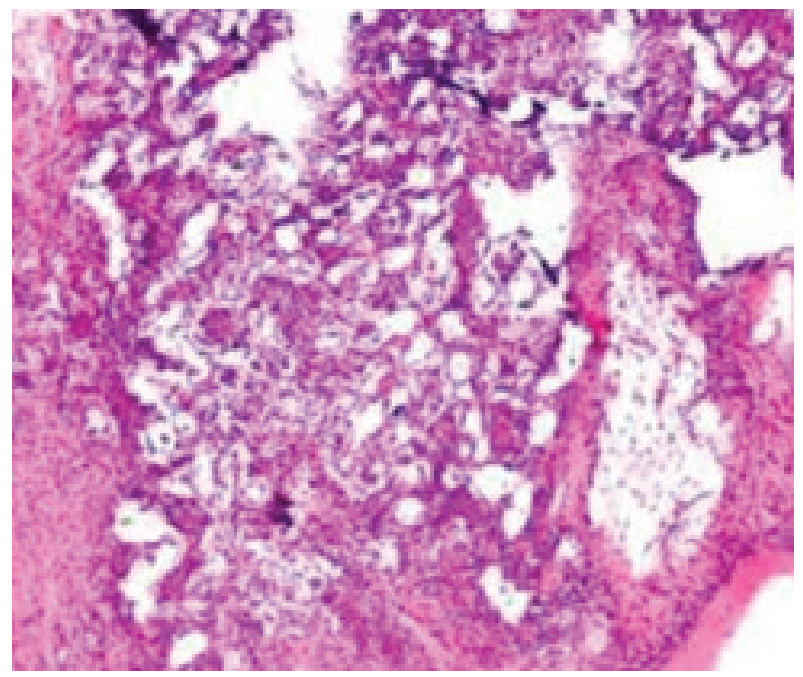

Fig-3 Showing histological slide of yolk sac tumour containing multiple endodermal sinuses and hyaline globules. 
discharged on $7^{\text {th }}$ post-operative day and referred to oncology department for further management $\&$ regular follow up.

\section{Discussion:}

Testicular tumors constitute $1 \%$ of solid tumors encountered in males. ${ }^{5}$ These tumors can be seminomatous or non-seminomatous. History of cryptorchidism or presence of an undescended testis is considered as the most important risk factor for developing testicular malignancy. As previously mentioned the undescended testis can be anywhere along its normal pathway of descent. An abdominal testis is four times more likely to undergo malignant degeneration than an inguinal testis. The cancer of undescended testes usually peaks in the third or fourth decade of life. So testicular cancer should be considered as the differential diagnosis of an abdominal mass in adult patients with a non-palpable testis.

Painless enlargement of the testis or abdominal mass, is the common mode of presentation in an undescended testis which was also the presentation of our patient. Rarely, an abdominal testicular tumour can cause acute abdomen, massive abdominal mass, pain, and haematuria because of adjacent visceral infiltration.

$\mathrm{LDH}, \beta$-hCG and $\alpha \mathrm{FP}$ are the recommended serum markers for the evaluation of testicular cancer. ${ }^{6}$ These markers are useful to evaluate the pathological patterns of testicular malignancy prior to surgery. $\alpha \mathrm{FP}$ elevation is detectable in 40-60\% advanced non seminomatous germ cell tumour (NSGCT) like yolk sac tumour. ${ }^{6} \beta$-hCG may be also elevated in all types of NSGCT. ${ }^{7}$ In the present case, both $\alpha \mathrm{FP}$ and beta $\beta$ - hCG levels were elevated.

Various imaging modalities are available to diagnose and stage of intraabdominal testicular neoplasm. Classically, ultrasonography (USG) of whole abdomen is done to diagnose intraabdominal testicular neoplasm which shows hypoechoic intratesticular mass, calcification and cystic changes. ${ }^{8} \mathrm{CT}$ scanning of the abdomen and the pelvis is a very sensitive tool for the metastatic evaluation, which deinitely helps plan the management .Chest $\mathrm{x}$-ray is needed for evaluation of blood born metastasis. ${ }^{8}$ In our case, USG of abdomen was done which was sufficient for diagnosis and management of the disease.

The yolk sac tumor (YST), also known as endodermal sinus tumour, is characterized by the presence of tissue that resembles the yolk sac, allantois or extraembryonic mesenchyme. ${ }^{9}$ It is the most common germ cell tumour in infants and children, accounting for $80 \%$ of germ cell tumors in this age group but it is uncommon in adult population. ${ }^{10}$ It is observed only in $2.4 \%$ of adult patients. ${ }^{10}$ And our case belongs to this rare entity where an adult male with undescended testis presented with intraabdominal yolk sac tumour.

Dramatic improvements have been observed during last twenty years in combating intraabdominal testicular neoplasm which resulted from the combination of effective diagnostic techniques, improvement in serum tumor markers, effective multi-drug chemotherapeutic regimens and modifications of surgical techniques. Regarding treatment, it should be noted that because of the low incidence of adult yolk sac tumour, there is no therapeutic consensus beyond orchiectomy which was done in our case. ${ }^{11} \mathrm{An}$ adjuvant treatment with 4 chemotherapy cycles can be performed with cisplatin, etoposide or ifosfamid which improves the overall prognosis of the patient. ${ }^{12}$ That's why we have referred the patient to oncology department.

\section{Conclusion:}

Postnatal examination is very important for detection of any congenital anomalies. An undescended testis, whenever possible, must be brought down into its normal scrotal position preferably within six months after birth. Our patient presented in adult life presented with a yolk sac tumour in the abdomen with absent testis in the same side of hemi-scrotum. Laparotomy and excision of the mass was done and he was referred to oncology department for further management. This condition could have been prevented if the patient had an early diagnosis and subsequent management. So early diagnosis and prompt management is required for better outcome and prognosis of the patients having undescended testis.

\section{References:}

1. Pottern LM, Brown LM, Hoover RN. Testicular cancer risk among young men: role of cryptorchidism and inguinal hernia. J Natl Cancer Inst 1985; 74:377-381.

2. Alshyarba MH. A giant intra-abdominal testicular seminoma. Biomed Res. 2010; 21(3):227-229.

3. Cristián Palma C, Cristóbal B, Maccioni R. Seminoma in an adult cryptorchid testis (intra-abdominal): a case report. Actas Urol Esp. 2007; 31(2):160-163. [PubMed] [4]

4. Shrestha B, Baidya JL. Unresolved abdominal mass. Kathmandu Univer Med J. 2009; 7(25):82-85. [PubMed]

5. Batata MA, Chu FC, Hilaris BS, Whitmore WF, Golbey RB, et al. Testicular cancer in cryptorchids. Cancer. 1982; 49: 1023-1030

6. Iwamura H, Hatakeyama S, Fukushi K, Sato T, Kojima Y. Testicular tumor arising in intra-abdominal testis which was not detected at prior orchidopexy: a case report. Hiniyokika Kiyo. 2013; 59: 189-193.

7. Chandrasekhar LV, Abdul Gaffer T, Venkatramana M, Ratho S. A Case of Teratocarcinoma in Abdominal Testis: A Case Report. Internet J Radiol. 2005; 4: 21-23

8. Dow JA, Mostafi TK. Testicular tumor following orchiopexy. South Med J. 1967; 60:193-195.

9. Cheng C, Cheng PS. Cryptorchidism with a large intraabdominal mass a challenge. Br J Urol 1993; 72:946-948

10. Siegel R, Naishadham D, Jemal A (2017) Cancer Statistics, 2017. CA Cancer J Clin 62(1): 10-29.

11. Haque MM, Siddique AB, Rabbani ABMG, Quasem MA, Rahman AKMG, Rahman MM. Yolk Sac Tumour in undescended intra-abdominal testis: a case report. TAJ: Journal of Teachers Association. 2005;18(2):131-133

12. Murcia M, Ontario KM, Pure Yolk Sac Testicular Tumor in an Adult Patient: Case Report. Oncol Cancer Case Rep. 2017;3:31-32. 